\title{
Neurotoxicity of acrylamide and its analogues and effects of these analogues and other agents on acrylamide neuropathy
}

\author{
PHILIPPA M. EDWARDS \\ Biochemical Mechanisms Section, Toxicology Unit, Medical Research Council Laboratories, \\ Carshalton, England
}

\begin{abstract}
Edwards, Philippa M. (1975). British Journal of Industrial Medicine, 32, 31-38. Neurotoxicity of acrylamide and its analogues and effects of these analogues and other agents on acrylamide neuropathy. N-Hydroxymethylacrylamide, N-methylacrylamide, and N,Ndiethylacrylamide produce peripheral neuropathy in rats. Seven other compounds related to acrylamide do not produce neuropathy. Rats given one of the three neurotoxic compounds are more susceptible to acrylamide. A regime for testing acrylamide analogues for neurotoxicity is suggested. DDT, phenobarbitone, or high dietary concentrations of vitamin A or $E$ have no effect on the development of acrylamide neuropathy in rats. Acrylamide produces neuropathy in hens but not in frogs or goldfish.
\end{abstract}

Acrylamide has a wide range of industrial uses and its toxicity to the nervous system in man has been recognized for some time (Fujita et al., 1960; Garland and Patterson, 1967; Auld and Bedwell, 1967; Takahashi, Ohara, and Hashimoto, 1971). A peripheral neuropathy can be produced in a variety of experimental animals by repeated dosing with acrylamide (McCollister, Oyen, and Rowe, 1964; Fullerton and Barnes, 1966; Hopkins, 1970) and is similar to the lesion in man.

This paper records further studies on the toxicity of acrylamide and its analogues. Among the chemical analogues of acrylamide investigated by Barnes (1970), N-methylacrylamide and N-hydroxymethylacrylamide were shown to produce some neurological disability in high doses but the purity of the compounds was not established. Hashimoto and Aldridge (1970) could not demonstrate any neurotoxicity of recrystallized $\mathrm{N}$-hydroxymethylacrylamide but showed that rats treated with this compound were more susceptible to acrylamide. This work extends these observations and includes the study of other analogues. The effect of giving rats very high doses of pure N-hydroxymethylacrylamide or other com- pounds related to acrylamide and the ability of these compounds to enhance the neurotoxicity of acrylamide have been studied. In industrial processes acrylamide analogues may be used with acrylamide, and it is therefore important to establish whether they increase susceptibility to acrylamide. A system for testing the neurotoxicity of acrylamide analogues has arisen from these studies. Compounds have been selected on the basis of their industrial use, reactivity with sulphydryl groups in vitro or structural similarity to acrylamide.

The claim that stimulation of the mixed function oxidases of the liver microsomes delays the onset of the neurological damage produced by acrylamide in the rat (Kaplan, Murphy, and Gilles, 1973) was examined. The influence of vitamins $A$ and $E$ on acrylamide neurotoxicity has also been studied.

Although many species appear to respond in a similar way to repeated exposure to acrylamide, attempts to produce neuropathy in hens had previously been unsuccessful (Barnes, unpublished data). It was of interest to examine the effects in hens because detailed studies of the neurotoxic action of organophosphorus compounds in hens 
have been carried out in this laboratory. The toxicity of acrylamide to cold-blooded species was examined because nerves from these animals might be more amenable than mammalian nerves to in vitro studies on the mode of action of acrylamide.

\section{Materials and methods}

\section{Chemicals}

Acrylamide, ethyl crotonate, methyl methacrylate, methylene-bis-acrylamide, and hydroquinone were obtained from BDH Ltd. (Poole). N-Bis-acrylamidoacetic acid was a gift from Bridge Chemicals Ltd. (Tonbridge). N-Hydroxymethylacrylamide was a gift from Vinyl Products Ltd. (Carshalton) and was recrystallized from ethanol and ethyl acetate. Reduced glutathione (Schwarz Mann) was obtained from MicroBio Laboratories Ltd. (London). Vitamin A (Rovimix A-500) and vitamin E (Rovimix E-25) were obtained from Roche Products Ltd. (London), phenobarbitone (sodium salt) from May and Baker (Dagenham), and DDT from Geigy (UK) Ltd. (Manchester). 3,3-Iminodipropionitrile was obtained from Eastman Organic Chemicals Ltd. (Liverpool); $\mathrm{N}$-methylacrylamide and $\mathbf{N}, \mathbf{N}$-diethylacrylamide were synthesized according to Koton et al. (1958). 3,3-Iminodipropionamide was prepared by converting 3,3-iminodipropionitrile to the dipropionic acid dimethyl ester which was then treated with liquid ammonia in methanol. The product was recrystallized from ethanol (MP $\left.145^{\circ} \mathrm{C}\right)$. Acrylic acid chloride was prepared by refluxing acrylic acid with thionyl chloride and purified by redistillation. $\mathbf{N}, \mathbf{N}-$ pentamethylene acrylamide was prepared by reacting acrylic acid chloride with piperidine and purified by redistillation (BP $96^{\circ} \mathrm{C}$ at $4 \mathrm{~mm}$ ). All acrylic compounds contained traces of hydroquinone to inhibit polymerization. S- $\beta$-Propionamido-glutathione was prepared by reacting acrylamide with glutathione at $\mathrm{pH} 8.0$ in the presence of potassium cyanide $\left(10^{-4} \mathrm{M}\right)$. The glutathione conjugate was purified by ion-exchange chromatography.

The purity of N-methylacrylamide, N,N-diethylacrylamide, and N-hydroxymethylacrylamide was established by gas-liquid chromatography and mass spectrometry; less than $0.05 \%$ acrylamide was present.

\section{Animals}

Male Porton rats (approximately $200 \mathrm{~g}$ in weight at the time of beginning dosing) in groups of four, adult Star Cross hens (approximately $3 \mathrm{~kg}$ in weight), male frogs (Rana temporaria), and goldfish were used.

\section{Diets and dosing}

Rats were fed powdered 4IB pellets to which the test compounds were added. In experiments using acrylamide or its analogues the diet mixture was prepared weekly. Compounds administered intraperitoneally were dissolved in $0.9 \%$ saline unless otherwise stated. Hens were dosed orally with acrylamide (50 $\mathrm{mg} / \mathrm{kg}$ ) dissolved in $0.9 \%$ saline three times a week.

Frogs were given acrylamide either by injection in saline into the dorsal sac or by exposing them to a solution containing acrylamide for various times and then rinsing them under running water. Goldfish were maintained in tanks containing various levels of acrylamide. The acrylamide level in the water was assayed at intervals by the method of Mattocks (1968). It decreased very rapidly in the presence of weed or algae, so permanganatecleaned, weed-free tanks were used for the majority of the experiments. The level of acrylamide in these remained fairly constant.

\section{Evaluation of neuropathy in rats}

In these experiments rats were taken from their cages three times a week and their movements were observed and recorded. Rats were judged to show slight disability when the first signs of ataxia were detected. Typically the hindlimbs appeared weak, were spread rather broadly, and were frequently used together, giving a hopping rather than a walking gait. The rats also slipped more frequently when walking over a formica-topped table and had a rather waddling gait.

Rats were judged to show moderate disability when they failed to bring the hindlimbs up under the body when walking. They frequently trailed their hind feet, which were often inverted.

Rats were judged to show severe disability when the hind legs were permanently trailed behind the body. There was usually urinary retention and incontinence at this stage, and abnormal positioning of the fore-paws could be observed.

\section{Histology of hen nervous tissue}

Two hens were killed with an overdose of pentobarbitone sodium and the sciatic nerve, spinal cord, and brachial plexus were removed for histology.

Effect of acrylamide analogues on acrylamide neurotoxicity

In most experiments rats were fed the analogue in the diet and given repeated intraperitoneal doses of acrylamide. In other experiments, the analogue was given by repeated intraperitoneal injections and the acrylamide was fed in the diet. A control group with the appropriate regime of acrylamide treatment was set up for each experiment. For the estimation of the relative potencies of active compounds, rats were given repeated intraperitoneal doses of either one of the analogues or various amounts of acrylamide. After the number of weeks indicated in the figure acrylamide was given in the diet in addition to the intraperitoneal dosing.

Effects of DDT and phenobarbitone on acrylamide neurotoxicity

Rats were given acrylamide in the diet and either DDT or phenobarbitone by intraperitoneal injection. A control group was given acrylamide only.

Effects of vitamins $A$ and $E$ on acrylamide neurotoxicity Vitamin $\mathbf{A}$ or vitamin $\mathbf{E}$ was added to the diet and given continuously from one week before giving repeated intraperitoneal doses of acrylamide. A control group was given unsupplemented 4IB powder and dosed with acrylamide in the same way.

\section{Results}

Toxicity of acrylamide analogues

The structures of the compounds and a summary of 
TABLE 1

Summary of Neurotoxicity of Compounds and of their Additive Effects With ACRylamide

\begin{tabular}{|c|c|c|c|c|}
\hline Compound & Formula & $\begin{array}{l}\text { Reactivity } \\
\text { with } \\
\text { glutathione }\end{array}$ & Neurotoxicity & $\begin{array}{l}\text { Enhancement of } \\
\text { acrylamide } \\
\text { neuropathy }\end{array}$ \\
\hline $\begin{array}{l}\text { Acrylamide } \\
\text { 1. Ethyl crotonate } \\
\text { 2. Methyl methacrylate } \\
\text { 3. Methylene-bis-acrylamide }\end{array}$ & $\begin{array}{l}\mathrm{CH}_{2}: \mathrm{CHCONH}_{2} \\
\mathrm{CH}_{3} \mathrm{CH}: \mathrm{COOC}_{2} \mathrm{H}_{5} \\
\mathrm{CH}_{2}: \mathrm{C}\left(\mathrm{CH}_{3}\right) \mathrm{COOCH}_{3} \\
\left(\mathrm{CH}_{2}: \mathrm{CHCONH}\right)_{2} \mathrm{CH}_{2}\end{array}$ & $\begin{array}{l}0 \cdot 91 \\
0 \cdot 24 \\
0 \cdot 17 \\
0 \cdot 54\end{array}$ & $\begin{array}{l}+ \\
- \\
-\end{array}$ & $\begin{array}{l}+ \\
- \\
-\end{array}$ \\
\hline 4. N,N-pentamethylene-acrylamide & $\mathrm{CH}_{2}: \mathrm{CHCON}$ & Not tested & - & - \\
\hline 5. N,N-bis-Acrylamido-acetic acid & $\begin{array}{l}\left(\mathrm{CH}_{2}: \mathrm{CHCONH}\right)_{2}^{-} \\
\mathrm{CHCOOH}\end{array}$ & Not tested & - & Not tested \\
\hline $\begin{array}{l}\text { 6. 3,3-Iminodipropionamide } \\
\text { 7. S- } \beta \text {-Propionamido-glutathione }\end{array}$ & $\begin{array}{l}\mathrm{NH}\left(\mathrm{CH}_{2} \mathrm{CH}_{2} \mathrm{CONH}_{2}\right)_{2} \\
\text { Glutathione-SCH} \\
\text { CONH }_{2} \mathrm{CH}_{2}\end{array}$ & Not tested & - & Not tested \\
\hline $\begin{array}{l}\text { 8. N-Hydroxymethylacrylamide } \\
\text { 9. N,N-Diethylacrylamide } \\
\text { 10. N-Methylacrylamide }\end{array}$ & $\begin{array}{l}\mathrm{CH}_{2}: \mathrm{CHCONHCH}_{2} \mathrm{OH} \\
\mathrm{CH}_{2}: \mathrm{CHCON}\left(\mathrm{C}_{2} \mathrm{H}_{5}\right)_{2} \\
\mathrm{CH}_{2}: \mathrm{CHCONHCH} 3\end{array}$ & $\begin{array}{l}0.91 \\
0.058 \\
0.058\end{array}$ & $\begin{array}{l}+ \\
+ \\
+\end{array}$ & $\begin{array}{l}+ \\
t \\
t\end{array}$ \\
\hline
\end{tabular}

'Values taken from Hashimoto and Aldridge (1970) given as the rate constant $\left(1 \mathrm{~mol}^{-1} \mathrm{~min}^{-1}\right)$. Compounds were tested for neurotoxicity and effects on acrylamide neuropathy as described in the text. indicates a positive result, - indicates a negative result.

the results are given in Table 1 . The following compounds produced no neuropathy in rats when fed in the diet at the concentrations and for the times shown below. The daily dose (calculated from food intake) received by the rats is given in parentheses.

1. Ethyl crotonate-18 $400 \mathrm{ppm}$ for 5 weeks (373 $\mathrm{mg} / \mathrm{rat}$ )

2. Methyl methacrylate-18 $800 \mathrm{ppm}$ for 5 weeks $(410 \mathrm{mg} / \mathrm{rat})$

3. Methylene-bis-acrylamide-1 $800 \mathrm{ppm}$, for 1 week $(23 \mathrm{mg} / \mathrm{rat})$ then $900 \mathrm{ppm}$ for a further 10 weeks $(21 \mathrm{mg} / \mathrm{rat})$

4. N,N-Pentamethylene-acrylamide $-1800 \mathrm{ppm}$ for 6 weeks ( $34 \mathrm{mg} / \mathrm{rat}$ )

5. N-bis-Acrylamido-acetic acid- $-900 \mathrm{ppm}$ for 5 weeks $(22 \mathrm{mg} / \mathrm{rat})$

Rats fed on methylene-bis-acrylamide were in poor general health and the initial concentration in the diet had to be reduced because the animals were losing weight. Rats given oral doses $(50 \mathrm{mg} / \mathrm{kg})$ five times a week failed to put on weight but there were no signs of weakness or ataxia up to three weeks. $\mathrm{N}$-bis-Acrylamido-acetic acid was also given by oral dosing $(128 \mathrm{mg} / \mathrm{kg}$ in a solution neutralized with sodium bicarbonate) five times a week. No ataxia was observed up to two weeks.

The following compounds produced no neuropathy in rats when dosed intraperitoneally at the doses and times given:

6. 3,3-Iminodipropionamide-134 $\mathrm{mg} / \mathrm{kg}$ three times a week for 12 weeks

7. S- $\beta$-Propionamido-glutathione $-568 \mathrm{mg} / \mathrm{kg}$ three times a week for 13 weeks
The following compounds in the diet produced peripheral neuropathy:

8. N-Hydroxymethylacrylamide at a concentration of $1800 \mathrm{ppm}$ (daily intake $27 \mathrm{mg} / \mathrm{rat}$ ) for one week and thereafter $900 \mathrm{ppm}$ (daily intake 18.6 $\mathrm{mg} / \mathrm{rat}$ ) produced slight ataxia after five weeks.

Over the next two weeks, in addition to the dosing via the diet, four intraperitoneal doses of $\mathrm{N}$ hydroxymethylacrylamide $(50 \mathrm{mg} / \mathrm{kg})$ were given. The disability became moderate at seven weeks.

9. N,N-Diethylacrylamide at a concentration of $800 \mathrm{ppm}$ (daily intake $19 \mathrm{mg} / \mathrm{rat}$ ) produced no signs of weakness or ataxia up to 10 weeks.

The concentration was increased to $1600 \mathrm{ppm}$ (daily intake $39 \mathrm{mg} / \mathrm{rat}$ ), and slight signs of ataxia were observed after a further two weeks. N,NDiethylacrylamide at a concentration of $980 \mathrm{ppm}$ (daily intake $23 \mathrm{mg} / \mathrm{rat}$ ) showed slight ataxia after eight to 10 weeks. After 13 weeks the rats were no worse, and two intraperitoneal doses of N,Ndiethylacrylamide $(90 \mathrm{mg} / \mathrm{kg})$ were given in week 14 . Moderate disability then developed over the next two to four days.

10. N-Methylacrylamide at a concentration of 980 $\mathrm{ppm}$ in the diet (daily dose $19 \mathrm{mg} / \mathrm{rat}$ ) produced slight disability after 4-5 weeks, which became moderate at 7-8 weeks. Two intraperitoneal doses of $\mathrm{N}$-methylacrylamide were given during week 9 and the disability became severe.

The neuropathy produced by these three compounds was indistinguishable from that produced by acrylamide, and after returning to a normal diet the rats slowly recovered. 
Effect of acrylamide analogues on the development of acrylamide neuropathy

When rats were given repeated doses of acrylamide and also given analogues in the diet, three compounds (N-hydroxymethylacrylamide, N,N-diethylacrylamide, and $\mathrm{N}$-methylacrylamide) hastened the onset of neuropathy (Table 2), that is, less acrylamide was required to produce neuropathy in rats fed these analogues than rats fed a normal diet. These rats failed to recover after withdrawal of acrylamide if maintained on a diet containing the analogue. Animals on a control diet began to recover from one week to ten days after withdrawal of acrylamide. Four other compounds had no effect on the neuropathy produced by dosing with acrylamide. Rats fed on methylene-bis-acrylamide were in poor condition and did not gain weight during dosing. It was very difficult to decide whether the neuropathy was in fact worse in these animals. 3,3-Iminodipropionamide was tested slightly differently. The acrylamide was given in the diet at $400 \mathrm{ppm}$, and 3,3-iminodipropionamide was given in twice weekly injections $(100 \mathrm{mg} / \mathrm{kg} \mathrm{IP})$ from one week before the acrylamide was begun. A control group was given acrylamide only. Both groups developed slight ataxia after 10 days which became moderate after 14 days. Of the eight compounds in all, only those which were neurotoxic when given alone (Table 1) increased the susceptibility of rats to acrylamide. The effects of these analogues on acrylamide neuropathy can probably be explained on the basis of an additive effect, although quantitative comparisons are difficult because of the differences in the time course of the development of neuropathy. This additive effect was used to obtain a more reliable value for the potencies of the three active compounds relative to acrylamide. The effects of these compounds on acrylamide neuropathy were compared with the effects of various levels of acrylamide itself (Fig. 1). This provides a kind of bracketing dose assay of potency: for exam-

TABLE 2

Effect of Acrylamide Analogues on Development of Acrylamide Neuropathy

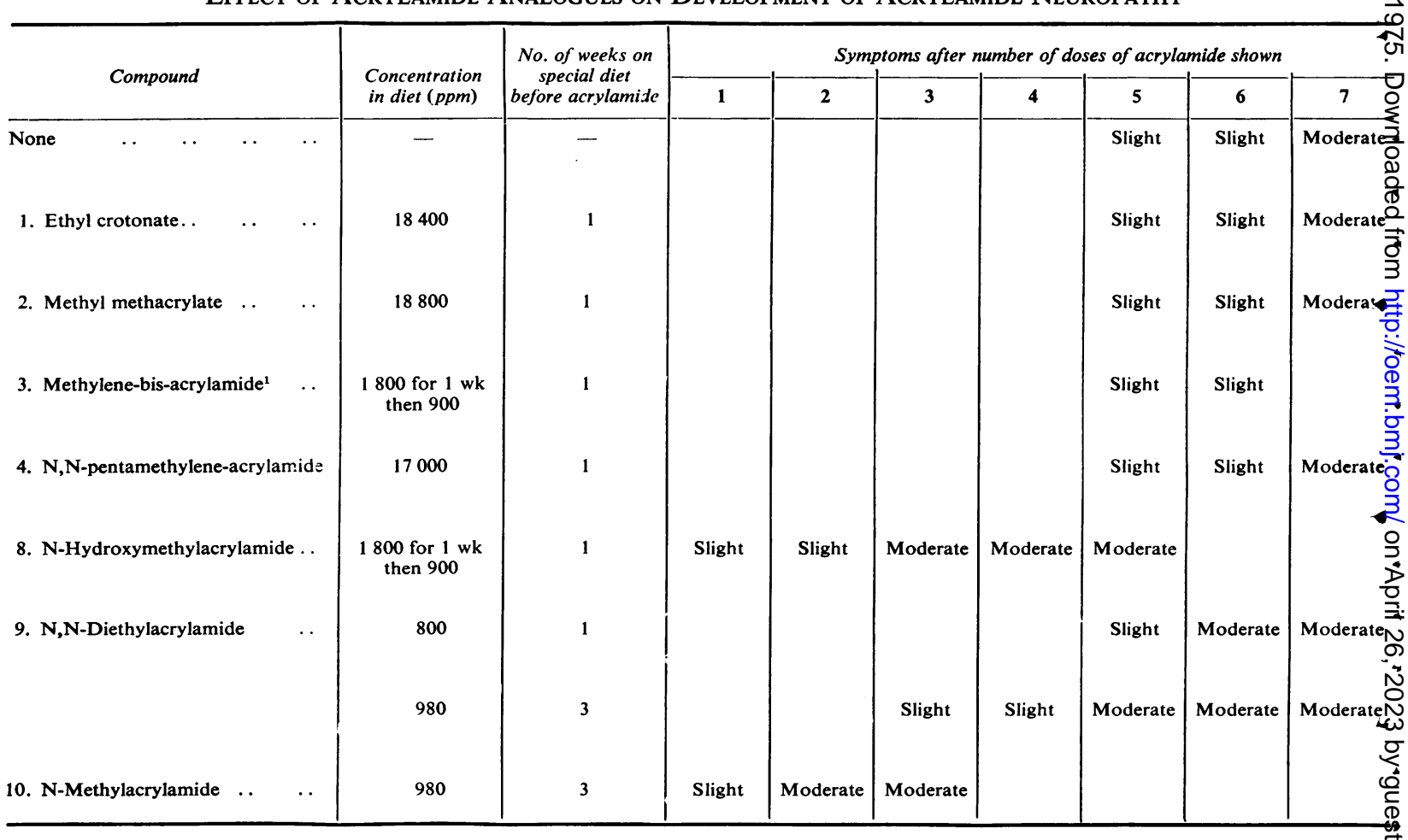

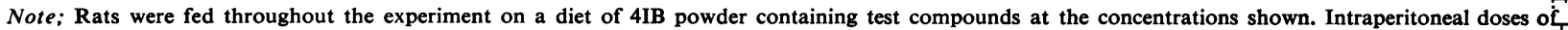

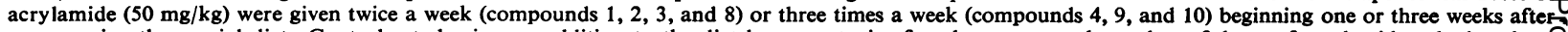

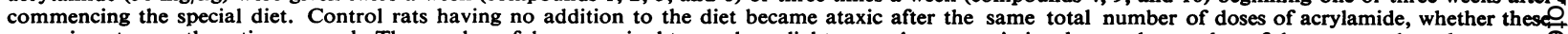

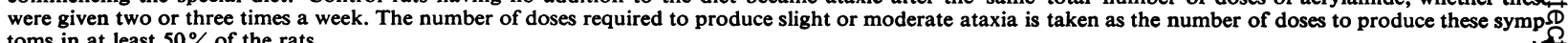
toms in at least $50 \%$ of the rats.

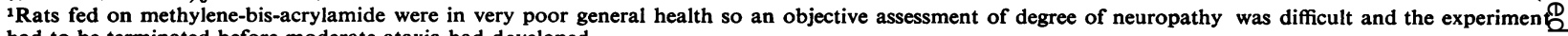
had to be terminated before moderate ataxia had developed. 


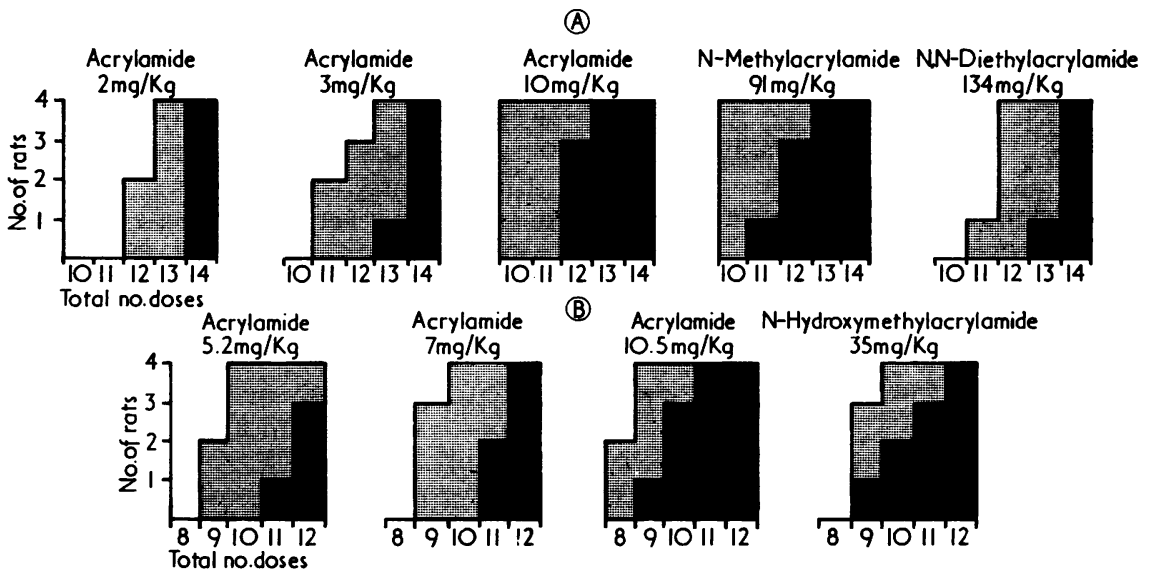

FIG. 1. Development of ataxia in rats fed acrylamide and given various additional doses of acrylamide, N-methylacrylamide, N,N-diethylacrylamide, and N-hydroxymethylacrylamide.

(A) The test compound (in arachis oil) or acrylamide standard was given (at the dose shown above each histogram) four times a week for one week then three times a week throughout the rest of the experiment. Treatment with acrylamide in the diet $(400 \mathrm{ppm})$ was begun two weeks after the first dose of the test compound or acrylamide standard. For each group the number of rats slightly (stippled) or moderately ataxic have been plotted against the sum of the doses given.

(B) The N-hydroxymethylacrylamide or acrylamide standard was given (at the dose shown above each histogram) three times a week. The treatment with acrylamide in the diet $(200 \mathrm{ppm})$ was begun 10 days after the first dose. For each group, the number of rats slightly (stippled) or moderately ataxic have been plotted against the sum of the doses given.

ple, in Fig. 1B the histogram for N-hydroxymethylacrylamide $(35 \mathrm{mg} / \mathrm{kg})$ has an appearance intermediate between that for acrylamide at $7 \mathrm{mg} / \mathrm{kg}$ and that for acrylamide at $10.5 \mathrm{mg} / \mathrm{kg}$. From this the approximate relative potencies of the two compounds can be calculated (Table 3 ). The values for the other two analogues in Table 3 are calculated similarly from Figure $1 \mathrm{~A}$.

Effects of DDT and phenobarbitone on acrylamide neurotoxicity

DDT and phenobarbitone are known to increase the metabolism of many toxic compounds by induction of the mixed function oxidase enzymes. One group of rats was given a single dose of DDT $(200 \mathrm{mg} / \mathrm{kg}$ IP in corn oil) five days before being given a diet containing $500 \mathrm{ppm}$ acrylamide.

Another group of rats was given phenobarbitone $(50 \mathrm{mg} / \mathrm{kg} \mathrm{IP})$ daily for nine days then five times a week throughout the rest of the experiment. On the sixth day of phenobarbitone dosing these animals were put on a diet containing acrylamide $(500 \mathrm{ppm})$. The control group was given acrylamide only. Slight ataxia developed in control and both experimental

TABLE 3

Relative Potencies of ACrylamide, N-Hydroxymethylacrylamide, N-METHYLACRYLAMIDE, AND N,N-DiETHYLACRYLAMIDE

\begin{tabular}{l|ccc}
\hline \multicolumn{1}{c|}{ Compound } & $\begin{array}{c}\text { Dose of analogue } \\
(\mathrm{mg} / \mathrm{kg})\end{array}$ & $\begin{array}{c}\text { Equivalent dose of } \\
\text { acrylamide }(\mathrm{mg} / \mathrm{kg})\end{array}$ & $\begin{array}{c}\text { Approximate potency as a } \\
\text { percentage of acrylamide }\end{array}$ \\
\hline N-Hydroxymethylacrylamide & 35 & $7-10$ & 30 \\
N-Methylacrylamide & 91 & 10 & 13 \\
N,N-Diethylacrylamide & 134 & 3 & 4 \\
\hline
\end{tabular}

The data in this table are derived from Fig. 1 by comparing the histograms of the analogues with those of different doses of acrylamide to obtain the dose of acrylamide which has approximately the same effect as the analogue.

The percentage potency is calculated from the ratio of moles of acrylamide to moles of analogue required to produce the same enhancement of acrylamide toxicity, that is, the ratio of the doses given in the first two columns of the table, corrected for molecular weight. 
groups after eight to 10 days on the acrylamide diet. All rats recovered at the same rate after stopping the acrylamide treatment.

Effects of vitamins $A$ and $E$ on acrylamide neurotoxicity

Supplementation of 4IB diet with vitamin A (5000 $\mathrm{IU} / \mathrm{kg})$ or vitamin $\mathrm{E}(52 \mathrm{IU} / \mathrm{kg})$ had no effect on neuropathy produced by dosing rats with acrylamide (50 mg/kg IP) twice weekly. Rats fed supplemented diet also recovered at the same rate as animals fed control diet after stopping the acrylamide dosing.

\section{Acrylamide toxicity in hens}

The susceptibility of individual hens to the neurotoxic action of acrylamide varied tremendously. Out of nine hens treated with acrylamide $(50 \mathrm{mg} / \mathrm{kg}$ orally three times a week), two showed slight ataxia after four doses, five after six doses, and two birds only after nine doses. All birds progressed to severe weakness and ataxia but at differing rates. Four hens were observed for several months after stopping acrylamide dosing when ataxia was severe; they appeared normal after two to three months. Histology of nerves from severely ataxic hens 'showed only scanty degeneration of nerve fibres in the sciatic and peroneal nerves and very little degeneration in the brachial nerves. Degenerating fibres were seen in the intramuscular bundles but the picture was badly obscured by adipose tissue. There was some degeneration in the spinocerebellar tracts in the cervical regions and in the medulla. A few degenerating fibres were seen in the cervical dorsal columns of the spinal cord' (Cavanagh, J. B., personal communication). The degree of spinal cord involvement in acrylamide neuropathy is therefore less than with the organophosphorus compounds, but only a limited degree of damage could be seen with the light microscope in all the nervous tissue examined. The nerve tissue damage produced by organophosphorus compounds is known to be related to reaction with a protein in brain which has esterase activity (Johnson, 1969). This esterase activity was measured in the brain of an ataxic hen 24 hours after the last dose of acrylamide. No inhibition was found.

\section{Acrylamide toxicity in frogs and goldfish}

Both species were sensitive to the general toxic effects of acrylamide. Three doses of $50 \mu \mathrm{g} / \mathrm{g}$ in one week killed three out of five frogs and a 2-hour exposure to a $2 \%(\mathrm{w} / \mathrm{v})$ solution of acrylamide killed two out of three frogs. No ill effects were seen in the survivors. Continuous exposure of goldfish to $100 \mathrm{ppm}$ acrylamide killed all seven in the group in five to seven days, but no effects were seen at $50 \mathrm{ppm}$ for up to 30 days. A variety of dosing and exposure regimes was used with both species, but no effects could be seen at sublethal doses.

\section{Discussion}

Three analogues of acrylamide, N-hydroxymethylacrylamide, N-methylacrylamide, and N,N-diethylacrylamide, free from contamination with acrylamide, given in large doses over a long period produce a peripheral neuropathy in rats. All these compounds have an additive effect with acrylamide (Table 1). Only the three compounds which produced neuropathy when given alone enhanced the neurotoxicity of acrylamide. It is not known whether the effect is strictly additive or synergistic, but the similarity of the chemical structures makes the former more likely. The failure of Hashimoto and Aldridge (1970) to produce neuropathy with N-hydroxymethylacrylamide alone was probably due to the fact that these workers used lower concentrations of the compound (1 $400 \mathrm{ppm}$ for one week, then $700 \mathrm{ppm}$ for seven weeks). Acrylamide itself in very low quantities $(10 \mathrm{mg} / \mathrm{kg}$ five times a week) did not produce ataxia for up to 116 doses (Fullerton and Barnes, 1966). These workers showed that there were some signs of regeneration of peripheral nerves in severely affected rats, fed $200 \mathrm{ppm}$ acrylamide, killed while acrylamide was still being given. This may also occur when high doses of weakly active compounds are given, resulting in either no signs of ataxia or an increase in the time (and hence the dose) required to produce ataxia. Therefore it is probably more reliable to test compounds which may have an acrylamide-like action by observing their effects on the development of acrylamide neuropathy. An approximate value for relative potency may also be made by this means.

The results indicate that although acrylamide can no longer be considered unique in its action, small alterations in structure result in considerable or complete loss of activity. The potency of the compound bears no relation to the reactivity with sulphydryl groups in vitro, as shown in Table 1 . It is interesting that compound 7(S- $\beta$-propionamidoglutathione), which is the product formed in vivo by the reaction of acrylamide with liver glutathione, was not toxic. Compound 6(3,3-iminodipropionamide) was studied because of its similarity to the neurolathyrogens but was found to be inactive.

Neither DDT nor phenobarbitone had any effect on the development of acrylamide neuropathy as assessed in these experiments, nor on the recovery. Kaplan et al. (1973) found that the onset of ataxia (assessed by failure of the rats to remain on a rotating rod) was delayed by these compounds. However, once these rats had developed ataxia they took longer to recover than rats given acrylamide alone. The extent of histological damage in these rats correlated better with the total dose of acrylamide given than with performance on the rotating rod. There are two major differences in the experimental 
procedures used in the studies of Kaplan et al. and those used in this study:

1. Kaplan et al. gave the acrylamide by daily intraperitoneal doses $(50 \mathrm{mg} / \mathrm{kg})$ whereas in the present experiments acrylamide was given in the diet (calculated daily dose $41 \mathrm{mg} / \mathrm{kg}$ );

2. the method of assessment of the neuropathy.

It is possible that the rotating rod test while having the advantage of being an objective and easily quantifiable assessment may be affected by factors other than the extent of nerve damage.

Deficiency in either vitamin A or E produces nerve damage (Pentschew and Schwarz, 1962; Aberle, 1934), and Prineas (1969) described the ultrastructural changes occurring in the nerves of acrylamide-treated rats as similar to those produced by vitamin $\mathrm{E}$ deficiency. However, the results in this paper indicate that acrylamide is not acting by producing a deficiency in these vitamins.

Hens given acrylamide developed a reversible weakness and ataxia but microscopically the damage to peripheral nerves was not extensive, even in hens severely disabled. Similar findings were obtained in rats by Suzuki and Pfaff (1973). This is consistent with the findings of Schaumburg, Wiśnieski, and Spencer (1974) that the earliest changes are in the nerve terminals which have degenerated, resulting in loss of functional activity in the nerve, before much change is observed in the nerve axons. Scanty degeneration of nerves in the central nervous system found in hens has also been observed in cats (Schaumburg, Wiśniewski, and Spencer, 1974) and rats (Suzuki and Pfaff, 1973). Neurotoxic organophosphorus compounds produce extensive degeneration of the spinal tracts in hens (Barnes and Denz, 1953) and there is little or no clinical recovery. It cannot be judged at present whether the reversibility of acrylamide neuropathy is a reflection of the lesser damage to the spinal cord, as compared with that caused by organophosphorus compounds, nor is it known whether the central nerves damaged by acrylamide undergo functional recovery. The initial biochemical event which leads to degeneration of the nerve is different in acrylamide and organophosphorus neuropathy, since the brain esterase which is specifically inhibited by all neurotoxic organophosphorus compounds is normal in hens treated with acrylamide.

It was hoped that nerves from cold-blooded animals might provide a suitable model for in vitro studies of nerve function. Studies on the responses of frogs and fish indicate that neuropathy cannot be produced with sub-lethal doses and therefore these animals do not provide a valid model for studying acrylamide neuropathy. Similar insensitivity of frogs to neurotoxic compounds has been found with organophosphorus (Edery and Schatzberg-Porath,
1960) and tribromimidazole compounds (Edwards, unpublished data).

I should like to thank Professor J. B. Cavanagh for the histological processing and evaluation of the chicken nervous tissue; Dr. A. R. Mattocks and Mr. R. Jones for synthesis of compounds $4,6,9$, and 10; Dr. R. Self for the analysis of acrylamide in active analogues; Dr. M. K. Johnson for the assay of neurotoxic esterase; and Miss M. A. Cash for skilled technical assistance.

\section{References}

Aberle, S. B. D. (1934). Neurological disturbances in rats reared on diets deficient in vitamin A. Journal of Nutrition, 7, 445-461.

Auld, R. B. and Bedwell, S. F. (1967). Peripheral neuropathy with sympathetic overactivity from industrial contact with acrylamide. Canadian Medical Association Journal, 96, 652-654.

Barnes, J. M. (1970). Observations on the effects on rats of compounds related to acrylamide. British Journal of Industrial Medicine, 27, 147-149.

__ and Denz, F. A. (1953). Experimental demyelination with organophosphorus compounds. Journal of Pathology and Bacteriology, 65, 597-605.

Edery, H. and Schatzberg-Porath, G. (1960). Studies on the effect of organophosphorus insecticides on amphibians. Archives Internationales de Pharmacodynamie et de Thérapie, 124, 212-224.

Fujita, A., Shibata, M., Kato, H., Aomi, Y., Ho, K., Nakazawa, T., and Takahashi, T. (1960). Clinical observations of three cases of acrylamide poisoning. Nippon Iji Shimpo, 1869, 27-40.

Fullerton, P. M. and Barnes, J. M. (1966). Peripheral neuropathy in rats produced by acrylamide. British Journal of Industrial Medicine, 23, 210-221.

Garland, T. O. and Patterson, M. W. H. (1967). Six cases of acrylamide poisoning. British Medical Journal, 4, 134-138.

Hashimoto, K. and Aldridge, W. N. (1970). Biochemical studies on acrylamide, a neurotoxic agent. Biochemical Pharmacology, 19, 2591-2604.

Hopkins, A. (1970). The effect of acrylamide on the peripheral nervous system of the baboon. Journal of Neurology, Neurosurgery and Psychiatry, 33, 805-816.

Johnson, M. K. (1969). The delayed neurotoxic effects of some organophosphorus compounds. Biochemical Journal, 114, 711-717.

Kaplan, M. L., Murphy, S. D., and Gilles, F. H. (1973). Modification of acrylamide neuropathy produced by selected factors. Toxicology and Applied Pharmacology, 24, 564-579.

Koton, M. M., Sokolova, T. A., Savitskaya, M. N., and Kiselever, T. M. (1958). Synthesis of N-substituted methacrylamides. Chemical Abstracts, 52, $6228 \mathrm{f}$.

Mattocks, A. R. (1968). Spectrophotometric determination of pyrazolines and some acrylic amides and esters. Analytical Chemistry, 40, 1347-1349.

McCollister, D. D., Oyen, F., and Rowe, V. K. (1964). Toxicology of acrylamide. Toxicology and Applied Pharmacology, 6, 172-181. 
Pentschew, A. and Schwarz, K. (1962). Systematic axonal dystrophy in vitamin E-deficient adult rats. Acta Neuropathologica, 1, 313-334.

Prineas, J. (1969). The pathogenesis of dying-back polyneuropathies. Journal of Neuropathology and Experimental Neurology, 28, 598-621.

Schaumburg, H. H., Wiśniewski, H. M., and Spencer, P. S. (1974). Journal of Neuropathology and Experimental Neurology, 33, 260-284.
Suzuki, K. and Pfaff, L. D. (1973). Acrylamide neuropathy in rats. Acta Neuropathologica, 24, 197-213.

Takahashi, M., Ohara, T., and Hashimoto, K. (1971). Electrophysiological study of nerve injuries in workers handling acrylamide. Internationales Archiv für Arbeitsmedizin, 28, 1-11.

Received for publication 13 June 1974

Accepted for publication 14 August 1974



(1)

